\title{
How Knowledge Inertia Influences Intent to Leave at Managerial Level in Organizations: Moderating Role of Tenure
}

\section{Selçuk Karayel iD a}

a Necmettin Erbakan University, Faculty of Political Sciences, Department of Management, Konya, Turkey. skarayel@erbakan.edu.tr

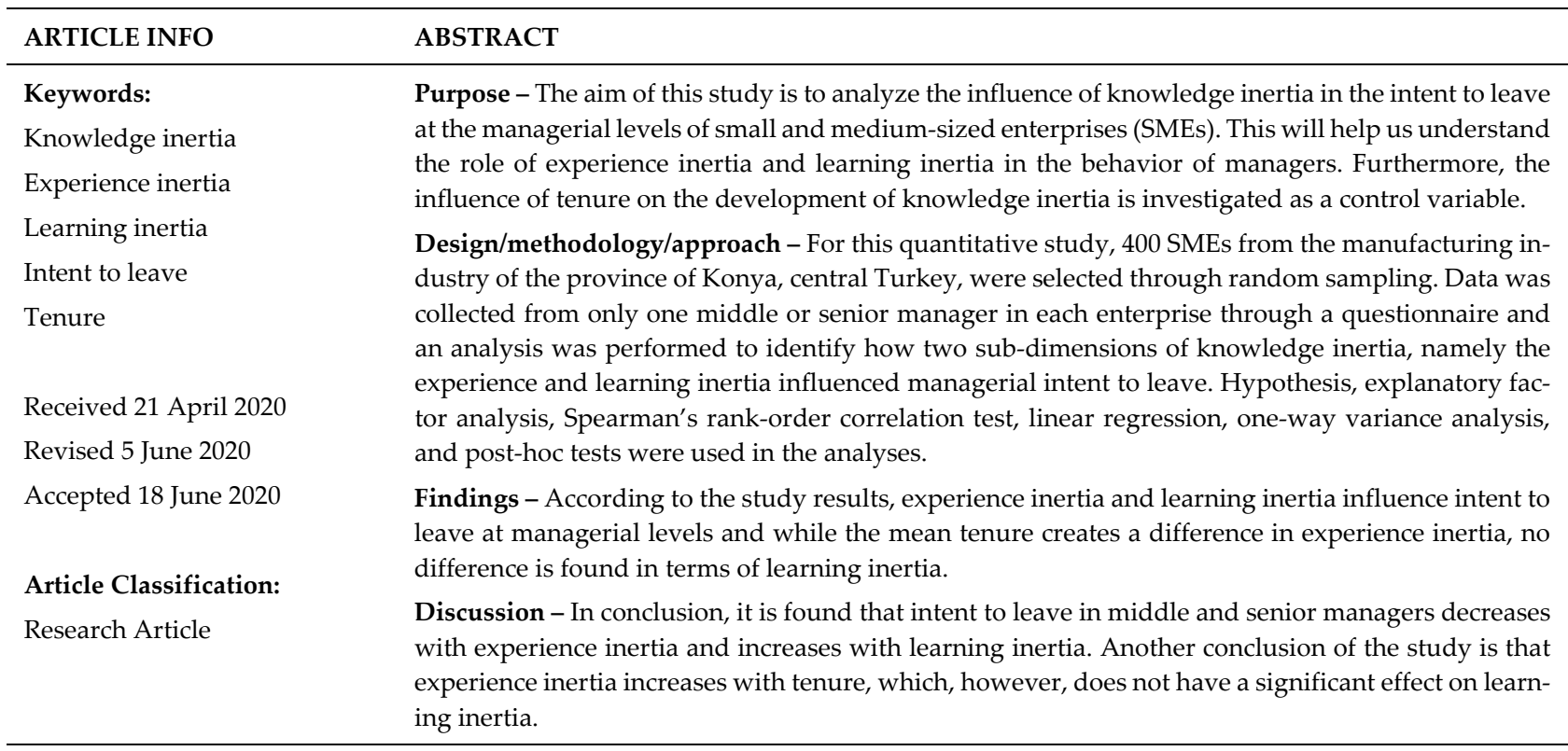

\section{Introduction}

Knowledge and knowledge management are increasingly important both for individuals and organizations. Knowledge, as power and resource, plays a crucial part at enterprise and individual levels. The power of knowledge is a vital resource to preserve the valuable heritage, to learn new things, solve problems, create core competencies and initiate new situations for individuals and businesses both now and in the future (Liao, 2003). Therefore, accurate and efficient management of knowledge is an important issue for businesses (Wang \& Yang, 2013). Organizational boundaries create inertia in time due to current data collection practices, systems, perceptions, expectations, and fears about data use (Liao, 2002).

Having acquired sufficient knowledge and experience, the workforce might resist changes that could render the said knowledge and experience less valuable (Delfgaauw \& Swank, 2016). The inertia effect of old routines and die-hard habits can be an obstacle to new learning processes in businesses or networks (Gertler \& Wolfe, 2002: 228). Once the circumstances surrounding the work function change, an individual manager's cognitive scripts may be incompatible with the changing nature of the situation. In such cases, manager's readily available, stable scenarios and associated habits may lead to dysfunction (Dane, 2010). After all, cognitive placement makes it hard to change habits. Finkelstein and Hambrick (1990) demonstrated a very serious relationship between senior managers' tenure and monotonous (permanent) strategies and performance, pointing out managers' tendency to act in accordance with industry averages. In this case, in an enterprise considered to follow monotonous strategies,

\section{Suggested Citation}

Karayel, S. (2020). How Knowledge Inertia Influences Intent to Leave at Managerial Level in Organizations: Moderating Role of Tenure, Journal of Business Research-Turk, 12 (2), 1878-1894. 
awareness and change cannot be expected from the senior management. Senior executives play a dominant role in formulating the corporate strategy (Westphal \& Frederickson, 2001).

Senior managers of a long shared tenure tend to develop a series of beliefs or "dominant logic" based on their common history in the business. Given the influence of the historical setting on the development of beliefs, senior managers often have difficulty adapting their mental models in rapidly changing environments, which in turn leads to poor organizational performance (Helfat, 2003: 395). It is possible to assert that managers bury themselves deep in a network of social commitments they created through social and psychological factors aimed at helping to increase cooperation in the first place (Sull et al., 1997).

Individuals refer to previous knowledge and experience to solve current problems. This type of routine problem solving strategy is called "knowledge inertia" (Liao et al., 2008; Wang \& Yang, 2013). The field literature includes many studies investigating the relation between knowledge inertia and change, innovation, performance, core competencies, leadership, outsourcing, decision making, or business models, etc. However, there is no study on its relation with the employees' intent to leave. Intent to leave involves significant costs for organizations (Djurkovic et al., 2008). Therefore, this study aims to provide new evidence on the premises and consequences of each component of knowledge inertia on managerial behavior. Subsequently, the first question to be researched in the study is as follows: How does knowledge inertia influence the intent to leave in middle and senior managers in the manufacturing industry? In this sense, the study has the potential to make various contributions to the literature. Figure 1 shows the theoretical model that forms the basis of the study.

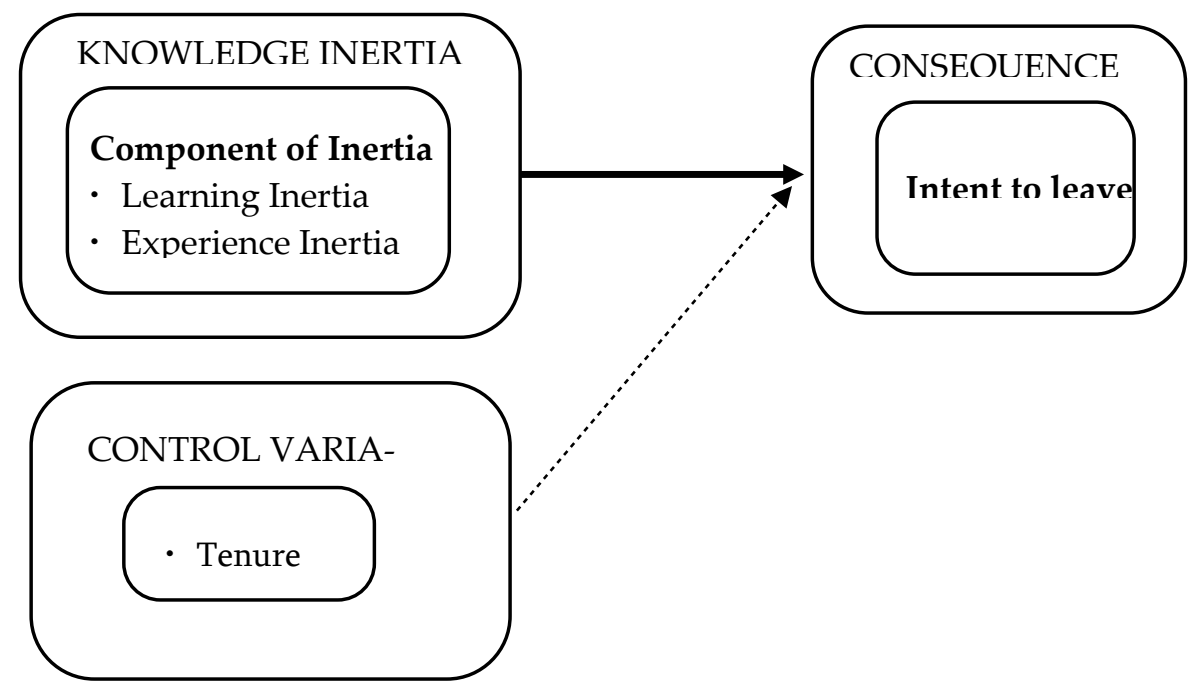

Figure 1. Theoretical Framework

\section{Knowledge inertia}

Knowledge is both power and resource for business. Information can be seen as something to be stored and manipulated, whereas knowledge is a process of knowing and acting simultaneously through expertise (Liao, 2002). Knowledge is the main competitive edge of a business (Hung, 2015). This requires managing knowledge and distributing it to other units and colleagues in the right time and in a correct manner (Xie, Fang, Zeng \& Huo, 2016). On the other hand, knowledge inertia can enable or disable the problem-solving ability of a business or individual (Tushman \& Anderson, 1986). 


\section{S. Karayel 12/2 (2020) 1878-1894}

Knowledge-based opinion researchers argue that knowledge is an important input and a source of value in the production process of a business (Hung, 2015). According to the same view, the existing knowledge base of a business limits its capacity to envisage radical innovations and apply new information (Zhou \& Li, 2012). Knowledge inertia in a competitive environment is dangerous, because it means predictability of each and every business policy and action by competitors (Liao et al., 2008).

Knowledge is an important source of power to learn new things, solve problems, and develop core competencies (Wu \& Lee, 2007). Once knowledge is internalized or institutionalized in organizations, it is hard to change (Nag, Corley \& Gioia, 2007). Human mind has a limited capacity to process new and complex information, which requires a high level of cognitive attention to process effectively (Gong et al., 2013).New problems are often evaluated using a kind of analogical reasoning. This is a mechanism to glean the knowledge of well-understood and already-solved problems and allocate it to a particular problem which is not familiar on the surface (Liao, 2002). Analogical reasoning or intuitive reasoning is like 'structure mapping', whereby identical relations between different objects are mapped. Mapping process involves one-to-one matching of a series of correspondence based on the similarities between proposals at a certain level of abstraction, patterning, and formation (Liao, 2002). Learning is influenced by ongoing knowledge; by the decisions made according to the criteria and facts kept in the information storage structures of knowledge distribution and by the interpretation of new information based on cognitive maps or schemes created through past experiences (O'Toole, 2010: 3).

Complex and new information is more prone to inertia and lack of communication across the business (Collinson \& Wilson, 2006). However, individuals often use their experience and prior knowledge for new problems and they develop similar solutions for similar problems. This common method of routine problem solving is called "knowledge inertia." These methods are often used to save time and effort and they are adapted to avoid risks. However, in a setting of intense competition, the predictability or accessibility of everything devised or implemented by everyone else may lead to waste and failure of business energy (Shalikar et al., 2011). Learning inertia means acquiring new knowledge to solve problems and thus breaking the cycle of thinking inertia. Employees in a stable business seek to solve problems by referring to available knowledge and experience, leading to knowledge inertia (Xie et al., 2016).

"Knowledge inertia," "learning inertia," and "experience inertia" are the subject of several studies with their resort to old knowledge or experience to solve new problems and unwillingness or inability to learn new approaches (Liao, Fei \& Liu, 2008). In general, employees with more experience and learning inertia can continue to search new sources of information, try new technologies, and improve innovative thinking, as well as the level of innovation itself (Xie et al., 2016). Knowledge inertia is a result of sticking with routine problem-solving procedures, static sources of information (Liao, 2002), and following past experience or knowledge. It may enable or disable problem solving ability at an individual level (Liao, 2002; Wu \& Lee, 2007). Similarly, managers who are not motivated to communicate or transmit information are expected to maintain their knowledge and hinder the transfer of knowledge with an instinctive defensiveness (Xie at al. 2016). Knowledge inertia can prevent applying knowledge in management and create resistance in the organization against learning and problem solving (Shalikar et al., 2011).

The extent of knowledge inertia is believed to be related to many aspects of individual's: (1) acceptable levels of "available knowledge"; (2) willingness to accept "new things"; (3) number of "drafts" in memory; (4) possibility and cost of verifying the reliability of new knowledge (Wang and Yang, 2013).

Influence factors of knowledge inertia can be generalized as organizational and individual. Organizational factors include centralization of the organization, information technology, etc., while individual factors include acceptable level of "available knowledge" and willingness to accept "new things" (Wang \& Yang, 2013).

Managers with certain implicit knowledge do not want to abandon their existing knowledge in favor of a new knowledge that may not serve their individual interests. And when they are not willing to acquire new knowledge, they tend to use their existing knowledge to solve their own problems (Hung, 2015). 


\section{S. Karayel 12/2 (2020) 1878-1894}

Studies on the organizational effects of knowledge inertia, it was found to have a positive effect on product innovation to reduce complexity and uncertainty (Tsai, Wu, Ma, Wu \& Zhou, 2019); that it moderated the correlation between organizational learning ability (Fang, Chang \& Chen, 2011; Tsai et al., 2019) and organizational innovation (Fang et al., 2011; Liao et al., 2008), and influenced organizational behavior (Tsai et al., 2019). In studies on its individual effects, knowledge inertia was found to be significantly correlated with entrepreneurial behavior (Koç, et al., 2014). Nevertheless, literature review throughout the study showed that the influence of knowledge inertia on intent to leave was not investigated.

\section{Learning inertia}

The socio-psychological perspective discusses the tendency of individuals to assume that learning new things is usually risky. Increasing work pressure can cause employees and managers to turn to familiar processes. This can be the case even when the employee wants something 'different' ('new') to get better results. In fact, employees may not be convinced at all that changing the behavior is worth the effort (Dievernich et al., 2016: 130).

Ineartia in learning and teaching comes when people think there is no need to acquire new knowledge by applying past experience and knowledge (Shalikar et al., 2011). If inertia develops in the process of learning and sharing knowledge, it blocks creative thinking on the part of employees, thus hindering the success of corporate management of knowledge (Wang \& Yang, 2013). Learning inertia can be defined as unwillingness to learn new ideas and approaches in solving the problems encountered in a new situation (Liao et al., 2008; Rahman \& Siswowiyanto, 2018). But it also affects the ability to learn and creative thinking, eventually eroding individuals' ability to innovate and to solve problems (Shalikar et al., 2011). As individuals' role in solving the problems at hand is limited and they cannot reasonably act on the knowledge they have about the environment, the cycle of learning is interrupted (Godkin, 2010). The learning inertia thus developed refers to the inertia of breaking or changing the tendency to learn new knowledge in order to use the existing one in problem solving (Wang \& Yang, 2013).

Organizational routines are a central theme in organizations that focus on the human factor. Organizational routines conceptualized by Stene (1940) are accepted as a fundamental tool in an organization's success (Feldman \& Pentland, 2003). The stabilizing effect of routines is important for learning. After all, it is this stability that furnishes the foundation to evaluate and compare change and to learn from it. Moreover, stability in organizational routines brings predictability, which in turn facilitates organizational coordination. It can thus be asserted that routines can turn into a competitive edge and help excellence become a permanent foundation of learning and decision making. Nevertheless, even though routines probably strengthen learning in the context of simple and operational tasks within an organization, they can cause more harm with their role in complex and strategic decisions (Castellaneta et al., 2018).

Chen, $\mathrm{Wu}, \mathrm{Mao}$, and $\mathrm{Li}$ (2017) suggest that in times of rapid economic change, organizational capacity to forget can be as important as the capacity to learn. Inertia built up over time in economic and social institutions with existing habits or practices can be an obstacle to the potential for new learning processes. Old thoughts and routine habits, even some norms and values may need to be destroyed so that existing social institutions can absorb new information (Gertler \& Wolfe, 2002: 21). In such a case, the need to 'forget' may be a precondition for learning ability. The inertia effect of the power of old routines and habits can hinder the ability to develop new learning processes in a business or network (p. 206).

In light of this information, the following hypothesis was formulated:

Hypothesis 1: Learning inertia has an influence on intent to leave.

\section{Experience inertia}

Some managers find it hard to give up their usual management styles, procedures, and technology (Grimes, 1994). Furthermore, people are happy when they know how to do something well, therefore they tend to resist seeking or adopting new methods (Robertson \& Langlois, 1994). If members of an organization are satisfied with the current situation, they are more likely to openly reject any suggestion in the direction of change. Giving up on old routines and practices can be emotionally difficult, after all (Andersén \& Andersén, 2014). Managers are limited 


\section{S. Karayel 12/2 (2020) 1878-1894}

in their rationality and this is the basis of the development of mental models and strategic beliefs that govern managerial decisions. It factors in the way managers contain problems and thus search for solutions (Helfat, 2003: 395).

The dominant thinking is that the static knowledge acquired from past experiences can help solve all other problems (Shalikar et al., 2011). Decision makers in this mindset rely on their memories of their past experience and knowledge for guidance in solving problems and making new plans (Rahman \& Siswowiyanto, 2018). Strategic choices are influenced by the personal background and previous experiences of senior managers (Westphal \& Frederickson, 2001).

Senior managers are under great pressure to perpetuate periods of strong financial performance. Therefore, they tend to maintain the status quo and the policies and strategies which proved successful in the past (Kline \& Wadhams, 2012). When business leaders invest heavily in certain areas, they can ignore and even stick with the mistakes related to their investments as they do not want to be associated with an error in their strategy (O'Toole, 2010: 125). Decision process influences strategic choices of managers and, by extension, the firm itself (Dean and Sharfman, 1996). Managers have a repertoire of actions to choose from and the choice may change according to the previous actions (Feldman, 2000). There is a strong tendency to simply repeat the most recent decision and this tendency to repeat is seen even in unethical behavior (Alós-Ferrer et al., 2016). Furthermore, a manager's ongoing, even increasing commitment to failed actions is associated with a need to control risk with optimism (Thomke \& Reinertsen, 1998).

Habits develop through repetition of certain behavior in a particular setting and represent how a person acts in response to a set of stimuli. Research shows that habits are represented and activated within individual's knowledge structures. They can particularly be cognitively coded as schemes related to frequently coded situations that enable individuals to interpret events and act appropriately in a given context (Dane, 2010). Cognitive structures and processes developed within the organizational framework are important in understanding strategic initiatives that can have consequences for the organization's strategic process, decisions, and performance (Moraes et al., 2018).

In general, the common way most people take to solve a problem in a dynamic environment is to match similar actions in the beginning. Matching or recognizing both existing and desired positions associated with a possible and previously used plan results from past experience or knowledge (Liao, 2002). This situation, also called experience inertia, points to individuals' inclination to use stored and conservative knowledge (Wang \& Yang, 2013) and experience (Liao et al., 2008; Rahman \& Siswowiyanto, 2018; Xie et al., 2015) to solve problems. In fact, this is related to human cognition maintaining views about a subject until new circumstances emerge to influence principles and conceptions. Human tendency to use past knowledge and experience in a new problem on account of time efficiency, limited resources, and risk avoidance is considered to be the main reason for knowledge inertia.

The literature on problem solving suggests that people who are triggered by previous experiences in similar situations prevent the consideration of the first choice of ideas and those who are trained to solve problems using a certain method cannot solve the problems that are similar in appearance, but differ in solution approaches. In short, people who have a problem to solve act with a fixed mindset when they encounter problems requiring alternative solutions (Dane, 2010).

Problem solving can actually be explained by similarity matching and analogical reasoning in terms of thinking, avoiding the risk of change, and saving time.

The hypothesis about the effect of experience inertia described above:

Hypothesis 2: Experience inertia has an influence on intent to leave.

\section{Intent to leave}

There is general consensus in the literature that the force that connects the individual to the organization is experienced as psychological conditions (García-Cabrera \& García-Soto, 2012). The personal and organizational costs 


\section{S. Karayel 12/2 (2020) 1878-1894}

of leaving work are very high. Consequently, it is not surprising that retention of employees is a point of focus for the senior management. Theoreticians and practicioners in social sciences still seek answers for the questions "Why do people leave?" and "Why do they stay?" (Mitchell et al., 2001). In fact, intent to leave is a combination of multiple commitments developed in the organizational context. In the model developed by Matier (1990: 41), factors influencing the decision to stay or leave include personal factors, push factors, and pull factors. Personal factors are the personal demographic variables such as need for employment, visibility, and job seeking tendency. On the other hand, push factors include intrinsic, material, and immaterial influences (Kim, Wolf-Wendel \& Twombly, 2013). Coomber and Barriball (2007) states that some factors lowering job satisfaction are difficult to control among reasons to leave. These include ineffective audit relations, weak opportunities for professional development, and leadership skills. Contrary to the intent to leave, there is evidence that the perceived support from the organization is positively correlated with employees' long-term commitment, organizational identity, loyalty, role performance, trust, organizational citizenship behavior, job satisfaction and intent to stay, but negatively correlated with absenteeism and leaving job (Djurkovic et al., 2008). In another similar study, Rosin and Korabik (1991) predicted a negative correlation of intent to leave with income, age, experience, and tenure, whereas age and expectations were positively correlated with satisfaction and loyalty.

The newest and most popular definition of organizational commitment is conceptualized in Meyer and Allen's (1991) three-component (emotional, normative, and continuation) commitments. From among the dimensions of organizational commitment, the sub-dimension of continuation is related to inertia-like forces that take shape over time and represent a broad constellation of influences on employee retention (García-Cabrera \& García-Soto, 2012). Kim et al. (2013) reported that employee decision to stay or leave is greatly influenced by inertia, whereas studies on the subject are not addressed empirically. Therefore, this study is considered a significant contribution to the literature.

The question in the study is whether the differences in tenure influence intent to leave on managerial levels.

The hypotheses formulated for this purpose are as follows for both dimensions of knowledge inertia:

Hypothesis 3: There is a difference between the average learning inertia and tenure of the managers in the same workplace.

Hypothesis 4: There is a difference between the average experience inertia and tenure of the managers in the same workplace.

Another point of interest is the relation of managerial tenure with knowledge inertia. Hypotheses formulated for this purpose:

\section{Research method}

\section{Sample and Procedures}

The universe of the study consists of a section of SMEs representing a variety of industries in the industrial province of Konya in Turkey. There are approximately 3,900 enterprises in the manufacturing sector in Konya (www.kso.org.tr). Study sample comprised of middle and senior managers randomly selected one from each of the manufacturing enterprises registered in the Konya Chamber of Industry. Managers occupied the position of general manager, production, marketing, finance, $R \& D$, or foreign trade manager in their enterprise. The survey was conducted in October-December 2019 and 400 valid returns were obtained. This corresponds to more than 10 answers per variable as recommended in the literature (Gürbüz \& Şahin, 2014).

The manufacturing sectors featured prominently in the study were agricultural tools, machinery, and equipment industry, automotive supply industry, basic metal industry, food products and beverages, leather and leather products, plastic and rubber products. Data was collected through face-to-face survey interviews with each potential participant.

Participant age: $20-30$ years (29.1\%), 31-40 years (35.1\%), $41-50$ years (24.6\%), and 51 and above (11.3\%). In terms of gender, $87.1 \%$ were male. Tenure in current job was reported as follows: Less than 1 year $(8.8 \%), 1-5$ years 


\section{S. Karayel 12/2 (2020) 1878-1894}

(36.5\%), 6-10 years (23.3\%), 11-15 years (12.3\%), and 16 years and longer (19.3\%). The scores were on a 5-point scale ranging from 1 (strongly disagree) to 5 (strongly agree).

\section{Measures}

Data were analyzed with the surveys of knowledge inertia and intent to leave. Both of these were evaluated as variables at an individual level. Dependent variable was intent to leave, independent variables were experience inertia and learning inertia, and control variable was tenure. Analysis was performed on the mean values of the answers involving dependent and independent variables.

\section{Knowledge inertia}

According to Liao et al. (2008), knowledge inertia has three dimensions: (1) learning inertia, (2) experience inertia, and (3) procedural inertia. Liao (2002) formulated the three-dimensional structure of knowledge inertia through his theoretical work, including procedural inertia, coaching inertia, and experience inertia. However, empirical research on the basis of theoretical work showed that knowledge inertia comprised only two dimensions as experience inertia and learning inertia and these dimensions were measured with 5-point Likert scale (Liao et al., 2008). Experience inertia and learning inertia scale includes seven items. Knowledge inertia was analyzed on this scale. The developers of the scale (Liao et al., 2008) found both dimensions of knowledge inertia highly reliable ( $\boldsymbol{\alpha}$ is above 0.70 ). The question "I can change my problem-solving approach according to suggestions and requests of other people" aimed at identifying the experience inertia sub-factor was corrected as it was reversed.

\section{Intent to leave}

The behavior of leaving job is generally evaluated in literature in two different ways: actual employee turnover rate and employee's intent to leave the organization (Turner \& Chelladurai, 2005). In this study, intent to leave was considered as a conclusive variable. After all, managers who plan to stay in the organization may eventually leave for various reasons. Therefore, intent to leave was used as the dependent variable. For intent to leave, a sixitem scale developed by Schwepker (2001) was used to measure the opinions of individuals in managerial positions about leaving the job. Schwepker took the intent to leave as one dimension and found the scale to be highly reliable (significance level is above 0.70 ).

\section{Tenure (control)}

Senior managers of a long shared tenure tend to develop a series of beliefs or "dominant logic" based on their common history in the business. Increased continuity intensifies role definition among group members and this in turn reduces interaction. Consequently, managerial tenure may influence the strategic decision making process (Fredrickson \& Iaquinto, 1989). Considering the effect of accumulation of experience on the development of beliefs, it is observed that senior managers find it hard to adapt their mindset and organizational performance decreases in rapidly changing environments (Tripsas \& Gavetti, 2000). Managers apply a strategy based on organizational paradigm within the framework of a common understanding (reinforcing their actions on the basis of past success stories and formation of routines) in light of their written and implicit knowledge. As the management team reinforces its continuity in the enterprise, managers get so socialized with the way they do business that their communication patterns become routine, environmental perceptions develop in unique ways and group members respond less to information that challenges existing decision-making process or its results (Fredrickson \& Iaquinto, 1989). In the questionnaire, a 5-point Likert scale was used for managerial tenure.

\section{Analysis}

The field literature does not contain any study on the influence of knowledge inertia on managers' intent to leave. The study uses quantitative methodology with explanatory approach and operates regression analysis to measure the impact of knowledge inertia to the intention to leave.

Research instrument was tested by using: [a] validity test, and [b] reliability test (using Cronbach alpha). Classical assumption is tested by using [a] normality test by using, skewness test, observing any clear pattern of Q-Q plot chart and variance coefficient $[\mathrm{b}]$ multicolinearity test by considering the Tolerance Value and Value Inflation 
Factor (VIF), and [c] heterocedasticity test by using Spearman's Rho coefficient and Scatterplot graphics. Meanwhile, hypothesis testing was undertaken by using [a] partial regression analysis (T-test) and, [b] multiple regression analysis (F-test).

\section{Descriptive factor analysis, reliability, and normalcy tests}

First, the normalcy assumption is checked to determine the dimensions of knowledge inertia. Variance coefficient was smaller than 0.30 (0.173), skewness and kurtosis values were within a limit of \pm 1.5 (Tabachnick, Fidell, 2007), no clear pattern was identified in the Q-Q plot chart and the number of data was greater than 30 (400), thus the distribution was considered normal (Kul, 2014). In the explanatory factor analysis (EFA) of the 14 items of knowledge inertia, a review of the component matrix table showed that one item of the experience inertia was in the dimension of learning inertia. Since the incompatibility of the scale with its original form and the fact that the item should have the experience inertia dimension, this item (item 1) was removed from the scale and EFA was repeated. Consequently, it was found that 13 items of knowledge inertia were distributed to two dimensions (experience inertia and learning inertia).

The specific contribution of each factor in the announced variance rate is greater than $5 \%$, with one factor containing more than three items. Two dimensions explain $47.322 \%$ of the total variance. Moreover, it was found that the contribution of all items to the common variance of the factors was greater than 0.10 .

Table 1. Internal consistencies and validity of scale constructs.

\begin{tabular}{|c|c|c|c|c|c|}
\hline Variable & & Knowledge inertia & Intent to leave & Learning inertia & Experience inertia \\
\hline Items & & 13 & 5 & 6 & 5 \\
\hline Cronbach alpha & & & 0.913 & 0.803 & 0.724 \\
\hline \multirow[t]{2}{*}{$\mathrm{KMO}$} & & 0.818 & 0.818 & & \\
\hline & $X^{2}$ & 1517.751 & 1737.013 & & \\
\hline \multirow[t]{2}{*}{ Bartlett's } & $\mathrm{df}$ & 78 & 15 & & \\
\hline & Sig. & 0.000 & 0.000 & & \\
\hline Determinant & & 0.017 & 0.010 & & \\
\hline $\begin{array}{l}\text { Total variance } \\
\text { explained }\end{array}$ & & & $64.788 \%$ & $26.694 \%$ & $20.628 \%$ \\
\hline
\end{tabular}

Validity test was used to measure the validity of the survey. This was done by finding the value of the corrected item-total correlation. As a rule, if the value of the corrected item-total correlation is greater than 0.3 , the questions are accepted as valid.

Reliability test was used to evaluate the reliability of the research tool used. If a question can be repeatedly used to measure the same item with predictably the same output each time, then that question is reliable. Cronbach alpha was used to test reliability. A value which is greater than 0.60 is reliable. As the smallest value was 0.724 in our analyses and findings, we could conclude that all the questions in our research tool were valid. 


\section{S. Karayel 12/2 (2020) 1878-1894}

A review of the correlations between the items in the learning inertia dimension showed that the correlation of one item (item 5) with the other items was very low. When that item was removed, the value of Cronbach alpha became 0.803 .

An item in the experience inertia dimension (item 3) correlated with the others very weakly and removing it increased Cronbach alpha to 0.724 . This value indicated that the scale had a good reliability (Futrell \& Parasuraman, 1984; Ingram \& Lee, 1990).

In the EFA analysis of the intent to leave scale, there is no Eigen value greater than 1 . It explains $64.78 \%$ of the total variance in a single dimension. The contribution of each item was greater than $10 \%$. The correlation value of one of the items (item 5) in the intent to leave was very low against other items. Removing it provided a good reliability (Cronbach alpha $=0.837)$.

As a result of explanatory factor analysis and reliability analysis, 2 items (items 1 and 3) were removed to reduce the 7-item experience inertia scale to 5 items; 1 item (item 5) was removed to reduce the 7-item learning inertia scale to 6 items, and 1 item (item 5) was removed from the 6 -item intent to leave which reduced it to 5 items. Table 1 provides information on the validity and factor loads of internal consistencies and scale structures of the items of knowledge inertia and intent to leave.

Table 2 shows the descriptive statistics and correlation matrix values of the variables in the analysis on the mean values of the items related to experience inertia, learning inertia, and intent to leave. In the coefficients table, both the constant variable and independent variables had significant coefficients. Experience inertia and learning inertia in the model showed a significant effect on intent to leave.

Table 2. Descriptive statistics and correlation matrix

\begin{tabular}{lccccccc}
\hline Variable & Mean & Std. Dev. & $\mathrm{N}$ & $\begin{array}{l}\text { Intent to } \\
\text { leave }\end{array}$ & $\begin{array}{l}\text { Learning } \\
\text { inertia }\end{array}$ & $\begin{array}{l}\text { Experience } \\
\text { inertia }\end{array}$ & Sig. \\
\hline Intent to leave & 1.7339 & 0.94856 & 388 & 1.0000 & 0.285 & -0.276 & 0.000 \\
Learning inertia & 1.9359 & 0.79205 & 388 & 0.285 & 1.0000 & -0.400 & 0.000 \\
Experience inertia & 4.1053 & 0.65115 & 388 & -0.276 & -0.400 & 1.0000 & 0.000 \\
\hline
\end{tabular}

\section{Multiple Linearity Test}

Multiple linearity testing is performed to measure any correlation between independent variables in the regression model. There should be no correlation between the independent variables of a regression model. If the value of the Variance Inflation Factor (VIF) is smaller than 2.5 and its tolerance is higher than 0.1, there is no multiple linearity in the model (Allison, 1999). According to the results of the multiple linearity test shown in Table 3, a VIF value of 1.145 and a tolerance value of 0.874 showed that independent variables (learning inertia, experiment inertia) did not correlate with each other.

\section{Heterocedasticity test}

Heterosedasticity test is used to determine any deviation in the assumption of heterocedasticity. In this context, deviation means the remainder in all observations of the variant inequality and regression model. There should be no signs of heterosedasticity in a regression model. Scatter plots were used in our regression model to prove there were no signs of heterosedasticity. In Figure 2, it was seen that a significant part of the residual points were not located below the axis $y(-3,+3)$ but were outside and that the residuals were not in the form of constant variance, nor were they evenly distributed around the axis y (Pituch \& Stevens, 2016). The presence of a heterosedasticity problem in the data set showed that the residuals did not fulfill the assumption of homoscedasticity. 


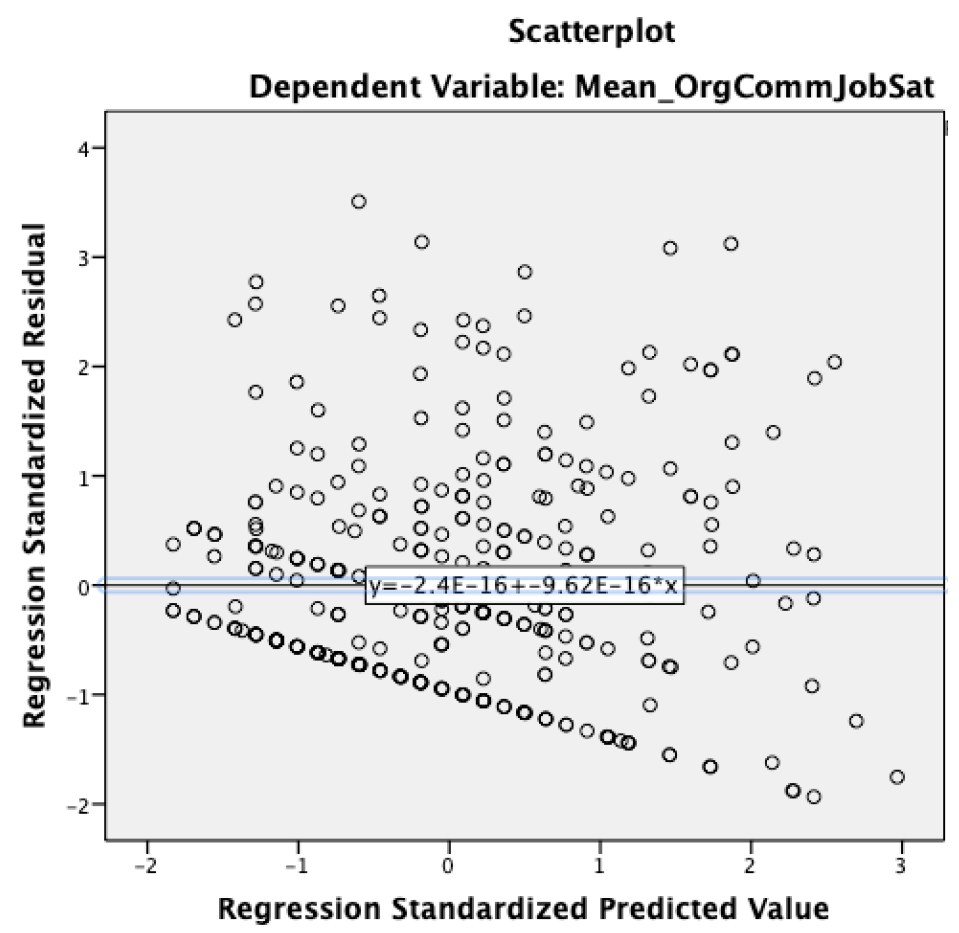

Figure 2. Scatter plot (regression standardized residual vs standardized predicted value)

\section{Weighted least squares regression analysis}

Weighted least squares regression is utilized where there's evidence of heteroskedastic errors that are associated with the least squares regression results. So we create a set of weights associated with each case of weights associated with each case that adjusts the contributions of those cases to the computation of the regression coefficients. More importantly to the standard errors this helps to create on unbiased standard errors for testing of the significance of the regression coefficients. A solution was developed for the heterosedasticity problem through weighted least squares (WLS) analysis. Absolute values of residuals were obtained and their unstandardized predicted values and weight values for WLS analysis were calculated. Thus, the homoscedasticity assumption of residuals was secured. Table 4 shows the results.

\section{Hypothesis testing (knowledge inertia vs intent to leave)}

For the hypothesis testing, the T-test, multiple regression analysis and F-test were performed.

\section{T-Test}

$\mathrm{T}$-Test is a test to measure the influence of one independent variable to the dependent variable. If the significant value is greater 0.05 , then it means that there is no influence of independent variable to dependent variable on the other hand if the significant value is less than 0.05 then it means there is an influence of independent variable to dependent variable. Results of t-test shown in the Table 3.

Table 3 shows that the $t(3.977)$ value in learning inertia variable is less than $0.05(\mathrm{p}=0.000)$. This means that learning inertia influences intent to leave. Experience shows that the value of $t(-3.673)$ and the significance value $(p=0.000)$ are less than 0.05 in inertia variable. This means that experience inertia influences intent to leave. 
Table 3. Coefficientsab

\begin{tabular}{lllllllll}
\hline & & \multicolumn{2}{c}{ Unst. Coeff. } & \multicolumn{2}{c}{ Std. Coeef. } & \multicolumn{3}{c}{ Collineraity Statistics } \\
Model & $\mathrm{B}$ & Std Error & Beta & $\mathrm{t}$ & Sig. & Tolerance & VIF \\
\hline 1 & (Constant) & 2.397 & 0.366 & & 6.542 & 0.000 & & \\
& Learning inertia & 0.252 & 0.063 & 0.208 & 3.977 & 0.000 & 0.874 & 1.145 \\
& Experience inertia & -0.265 & 0.072 & -0.192 & -3.673 & 0.000 & 0.874 & 1.145 \\
\hline
\end{tabular}

a. Dependent Variable: Intent to leave

b. Weighted Least Squares Regression - Weighted by weight

\section{F-test}

The F-test (multiple regression test) aims to measure the simultaneous relationship between independent and dependent variables in a research. Considering the significance value of 0.05 , in this test the ANOVA (Variance Analysis) table was used.

In the analysis with Table 4 weighted least squares, ANOVA Test, F (24.407) value, and significance value (0.000) were smaller than 0.05 , meaning that the value of $\mathrm{F}$ was significant. Table 4 shows that at least one sub-dimension of knowledge inertia in the model had a significant influence on the intent to leave.

Table 4. ANOVAab (regression and residual)_Weighted Least Square Regression

\begin{tabular}{|c|c|c|c|c|c|c|}
\hline & & Sum of Squares & $\mathrm{df}$ & Mean Square & $\mathrm{F}$ & Sig. \\
\hline \multirow[t]{3}{*}{1} & Regression & 79.763 & 2 & 39.882 & 24.407 & $0.000^{c}$ \\
\hline & Residual & 629.112 & 385 & 1.634 & & \\
\hline & Total & 708.875 & 387 & & & \\
\hline
\end{tabular}

a. Dependent Variable: Intent to Leave

b. Weighted Least Squares Regression - Weighted by weight

c. Predictors: (Constant), Learning Inertia, Experience Inertia

Table 4 shows the positive effect of learning inertia on the intent to leave. In other words, as learning inertia increases, managers' intent to leave strengthens. Nevertheless, it was found that experience inertia had a negative effect on the intent to leave. In other words, as experience inertia increases, managers' intent to leave weakens. As seen in Table 4, a 1-unit increase in learning inertia caused an increase of 0.208 units in the intent to leave, whereas a 1-unit increase in experience inertia led to a decrease of 0.192 units in intent to leave. In the presence of more than one argument, the adjusted-R-Square value shows the extent independent variables account for the dependent variable. Knowledge inertia accounts for intent to leave at a ratio of $10.8 \%$. This result showed that experience and learning inertia, as the sub-dimensions of knowledge inertia were an influence on managers' intent to leave. Moreover, it was observed that experience inertia was inversely proportional with the intent to leave and directly proportional with learning inertia. As a result, Hypothesis 1 and Hypothesis 2 were rejected.

\section{Hypothesis testing (knowledge inertia vs working experience duration)}

One-way variance analysis (ANOVA) is performed to find out whether mean values of the sub-dimensions of knowledge inertia differ with the tenure. For Hypothesis 3 and Hypothesis 4, first the normalcy assumption of the data, homogeneity of the variants, one-way variance analysis (ANOVA), and, if necessary, post-hoc tests were performed. 


\section{Normalcy analysis}

Whether the skewness and kurtosis values are within the limits of \pm 1.5 (Tabachnick and Fidell, 2007), the shape of the Q-Q plot chart, and a data set larger than $30(\mathrm{Kul}, 2014)$ are the criteria sought for the normal distribution of a data set. The skewness (0.372) and kurtosis (-1.039) values of the data set of managerial tenure were within the limits of \pm 1.5 , there was no obvious pattern in the Q-Q plot chart, and the normalcy assumption was provided because the number of data was greater than $30(n=400)$. Table 5 shows the descriptive statistics of the data set.

Table 5. Descriptive statistics of tenure of knowledge inertia

\begin{tabular}{lllllll}
\hline & \multicolumn{2}{c}{ Experience inertia } & \multicolumn{3}{c}{ Learning inertia } \\
& $\mathrm{N}$ & Mean & Std. Deviation & $\mathrm{N}$ & Mean & Std. Deviation \\
\hline Less than 1 year & 35 & 4.0590 & 0.88366 & 35 & 1.6571 & 0.74967 \\
1-5 year & 146 & 3.9199 & 0.76093 & 146 & 2.0199 & 0.85036 \\
6-10 year & 93 & 4.1591 & 0.55838 & 91 & 2.0110 & 0.77292 \\
$11-15$ years & 49 & 4.1500 & 0.57264 & 49 & 1.7823 & 0.59044 \\
16 and up year & 77 & 4.2900 & 0.69263 & 77 & 1.8840 & 0.79206 \\
\hline
\end{tabular}

\section{Testing homogeneity of variances}

Levene test is used to check the hypothesis that the variances of the variables calculated for two or more groups are equal, i.e. the zero hypothesis (Levene, homoscedasticity) on the equality of the variances of populations (Levene, 1960). Levene test is used before comparing the mean values. If the sig (p) value is greater than 0.05 , then there is no difference; that is, if the variances are equal, the Tukey test and if they are not equal, the Games-Howell is preferred.

Table 6. Levene test results

\begin{tabular}{llll}
\hline & Levene Statistics & Sig. & Post-Hoc Test \\
\hline Learning Inertia & 1.659 & 0.159 & TUKEY test \\
Experience Inertia & 2.886 & 0.022 & Games-Howell \\
\hline
\end{tabular}

\section{Test of difference}

As a result of ANOVA test in Table 7, it is seen that there is a difference between the mean experience inertia $(\mathrm{F}=4.106 ; \mathrm{p}=0.003)$ resulting from shared tenure, but there is no difference between the mean learning inertia $(\mathrm{F}=2.278 ; \mathrm{p}=0.060)$. In other words, it was concluded that tenure was a factor in the formation of experience inertia, but it had no effect on the mean learning inertia. Consequently, Hypothesis 3 was accepted and Hypothesis 4 was rejected. 
Table 7. ANOVA for experience inertia and learning inertia

\begin{tabular}{|c|c|c|c|c|c|c|c|c|c|c|}
\hline & \multicolumn{5}{|c|}{ Experience inertia } & \multicolumn{5}{|c|}{ Learning inertia } \\
\hline & $\begin{array}{l}\text { Sum of } \\
\text { squares }\end{array}$ & $\mathrm{df}$ & $\begin{array}{l}\text { Mean } \\
\text { square }\end{array}$ & F & Sig. & $\begin{array}{l}\text { Sum of } \\
\text { squares }\end{array}$ & $\mathrm{df}$ & $\begin{array}{l}\text { Mean } \\
\text { square }\end{array}$ & $\mathrm{F}$ & Sig. \\
\hline Between groups & 7.959 & 4 & 1.990 & 4.106 & 0.003 & 5.613 & 4 & 1.403 & 2.278 & 0.060 \\
\hline Within groups & 191.391 & 395 & 0.485 & & & 242.140 & 393 & 0.616 & & \\
\hline Total & 199.350 & 399 & & & & 247.753 & 397 & & & \\
\hline
\end{tabular}

Post-Hoc test

Table 8 shows the results of the Games-Howell post-hoc test performed to find out which group was responsible for the difference between tenure with a confidence of $99 \%$. An analysis of the data presented in Table 8 shows that those working in the same workplace between 1-5 years have lower experience inertia than those working for 16 years and over.

Table 8. Multiple comparisons: Working experience duration vs experience inertia

\begin{tabular}{|c|c|c|c|c|c|c|}
\hline \multirow[b]{2}{*}{$\begin{array}{l}\text { Working experience dura- } \\
\text { tion (I) }\end{array}$} & \multirow[b]{2}{*}{ Tenure (J) } & \multirow[b]{2}{*}{$\begin{array}{l}\text { Mean Dif- } \\
\text { ference } \\
(\mathrm{I}-\mathrm{J})\end{array}$} & \multirow[b]{2}{*}{$\begin{array}{l}\text { Std. } \\
\text { Error }\end{array}$} & \multirow[b]{2}{*}{ Sig. } & \multicolumn{2}{|c|}{ 99\% Confidence interva } \\
\hline & & & & & $\begin{array}{l}\text { Lower } \\
\text { Bound }\end{array}$ & $\begin{array}{l}\text { Upper } \\
\text { Bound }\end{array}$ \\
\hline Less than 1 year & $1-5$ year & 0.13918 & 0.16210 & 0.910 & -0.4203 & 0.6986 \\
\hline Less than 1 year & 6-10 year & -0.10009 & 0.16020 & 0.970 & -0.6546 & 0.4544 \\
\hline Less than 1 year & $11-15$ years & -0.09095 & 0.17030 & 0.983 & -0.6741 & 0.4922 \\
\hline Less than 1 year & 16 and up year & -0.23100 & 0.16894 & 0.651 & -0.8096 & 0.3476 \\
\hline $1-5$ year & 6-10 year & -0.23928 & 0.08555 & 0.044 & -0.5210 & 0.04224 \\
\hline $1-5$ year & $11-15$ years & -0.23014 & 0.10324 & 0.177 & -0.5746 & 0.1144 \\
\hline $1-5$ year & 16 and up year & $-0.37018^{*}$ & 0.10098 & 0.003 & -0.7042 & -0.0362 \\
\hline 6-10 year & $11-15$ years & 0.00914 & 0.10022 & 1.000 & -0.3265 & -0.3448 \\
\hline 6-10 year & 16 and up year & -0.13090 & 0.09789 & 0.668 & -0.4555 & 0.1937 \\
\hline 11-15 years & 16 and up year & -0.14004 & 0.11368 & 0.733 & -0.5188 & 0.2388 \\
\hline
\end{tabular}

a. The mean difference is significant at the 0.01 level

Results 


\section{S. Karayel 12/2 (2020) 1878-1894}

In conclusion, it is clearly seen that experience inertia and learning inertia as the sub-dimensions of knowledge inertia have an influence on managers' intent to leave and account for their intent to leave to the ratio of $10.8 \%$. However, these two types of inertia have opposing effects on managers' intent to leave. It was concluded that increased experience inertia in managers weakened intent to leave, whereas increase in learning inertia caused a heightened intent to leave at managers.

As for the effect of tenure, it was found that knowledge inertia increased parallel to tenure (when employees working for 16 years are compared to those with tenure of 1 to 5 years) however tenure had no significant effect on learning inertia.

\section{Discussion}

The study finding that increased experience inertia weakening managers' intent to leave can be linked to their unwillingness to disrupt routine, desire to maintain habits, tendency to keep technological competencies, degree of satisfaction with current status, desire to maintain the satisfaction with the power and status, desire to reap the benefits of favorable business, if any, and need to avoid risk. The fact that more than $60 \%$ of the managers participating in the study were aged 45 years and older only strengthens this assumption. However, the assumption still needs to be supported with empirical study.

The positive effect of learning inertia on the intent to leave may be associated with the risk perceived in connection with new things, the perception that learning new things is not worth the effort, the cognitive structure that new information is not useful in innovating and solving problems. However, since the correlation between the intent to leave and inertia was not investigated in the literature review, new studies are needed to support these findings.

Organizational learning performance improves when team members in a business have either less learning inertia or more experience inertia (Liao et al., 2008). Therefore, decision-makers in businesses need to identify policies to reinforce organizational learning and support the experience inertia to reduce intent to leave (voluntarily leaving the job).

According to Fredrickson \& Iaquinto (1989), changes in organization size and managerial tenure and team continuity are associated with changes in the enterprise's degree of detail and inclusiveness in taking and integrating strategic decisions. As these changes continue, rational strategic decision-making processes evolve into a process called creepy rationality. Furthermore, extensive research on social psychology and organizational behavior shows that tenure in a business is related to psychological commitment to status quo, including adherence to current business strategy (Westphal \& Frederickson, 2001). In short, various authors previously admitted the relation between managerial tenure and experience inertia, if not explicitly. Study results support the view of experience inertia, which leads to problem of inability to observe and perceive the changes in the business environment, causing excessive rationality in managerial levels, as expressed by Fredrickson and Iaquinto; thus, tenure has a both weak and significant relation with experience inertia.

A measure to take in this direction is to questioning the existence of the old management team (Fredrickson \& Iaquinto, 1989) in order to avoid the harmful effects of knowledge inertia in the business and to develop new and unique strategies. Within the framework of the view that sees information as the sole source of competitive advantage of the business, it should seek ways to strengthen the development of information within the organization and pay more attention to the organization and individual innovation.

The question of knowledge inertia can only be resolved by updating and sharing knowledge. Empowerment of learning agents (managers assuming this task) in businesses can provide a way to break knowledge inertia. Friedman (2003) defines the characteristics associated with learning agents as follows: they are proactive but reflective, realistic about limitations but have high aspirations, and they have a unique and original perspective (Godkin, 2010).

If 'everything' in the business relies on past experience and knowledge without any revision or update, the problem-solving method can be predicted and rendered ineffective by competitors. Others track down and inactivate 


\section{S. Karayel 12/2 (2020) 1878-1894}

the algorithm you conceive and develop, after all (Liao, 2002). This may end up in losing competitive edge and closing down business as an inevitable situation.

\section{Study Consideration}

Many factors other than job satisfaction, organizational commitment, and business alternatives need to be studied to analyze intent to leave at the managerial levels. Considering this is a pioneering study in evaluating the concepts of inertia and leaving job, it can be concluded that the repeating the study with larger samples and in a further variety of industries can be beneficial for the field literature by adding depth to it. For this purpose, as various components of knowledge inertia are thought to have different effects on the behavior of managers, it is also necessary to examine how these components influence the intent to leave. Furthermore, the addition of business performance as a control variable can be a great contribution by making it possible to measure how performance influences intent to leave and inertia.

\section{References}

Allison, P. D. (1999). Multiple regression: A primer. Pine Forge Press.

Alós-Ferrer, C., Hügelschäfer, S., \& Li, J. (2016). Inertia and decision making. Frontiers in psychology, 7, 169.

Andersén, J., \& Andersén, A. (2014). Deconstructing resistance to organizational change: a social representation theory approach. International Journal of Organizational Analysis. 22(3), 342-355

Castellaneta, F., Valentini, G., \& Zollo, M. (2018). Learning or inertia? The impact of experience and knowledge codification on post-acquisition integration. Industrial and Corporate Change, 27(3), 577-593.

Chen, S., Wu, S., Mao, C., \& Li, B. (2017). Strategic Adjustment Capacity, Sustained Competitive Advantage, and Firm Performance: An Evolutionary Perspective on Bird Flocking and Firm Competition. Mathematical Problems in Engineering, 2017.

Collinson, S., \& Wilson, D. C. (2006). Inertia in Japanese organizations: Knowledge management routines and failure to innovate. Organization Studies, 27(9), 1359-1387.

Coomber, B., \& Barriball, K. L. (2007). Impact of job satisfaction components on intent to leave and turnover for hospital-based nurses: a review of the research literature. International journal of nursing studies, 44(2), 297314.

Dane, E. (2010). Reconsidering the trade-off between expertise and flexibility: A cognitive entrenchment perspective. Academy of Management Review, 35(4), 579-603.

Dean Jr, J. W., \& Sharfman, M. P. (1996). Does decision process matter? A study of strategic decision-making effectiveness. Academy of management journal, 39(2), 368-392.

Delfgaauw, J., \& Swank, O. H. (2016). Task-Specific Human Capital and Organizational Inertia. Journal of Economics $\mathcal{E}$ Management Strategy, 25(3), 608-626.

Dievernich, F. E., Tokarski, K. O., \& Gong, J. (2016). Change Management and the Human Factor. Springer International Pu.

Djurkovic, N., McCormack, D., \& Casimir, G. (2008). Workplace bullying and intention to leave: the moderating effect of perceived organisational support. Human Resource Management Journal, 18(4), 405-422.

Fang, C. H., S. T. Chang, \& G. L. Chen. 2011. Organizational Learning Capacity and Organizational Innovation: The Moderating Role of Knowledge Inertia. African Journal of Business Management, 5(5): 1864-1870.

Feldman, M. S. (2000). Organizational routines as a source of continuous change. Organization science, 11(6), 611629. 


\section{S. Karayel 12/2 (2020) 1878-1894}

Feldman, M. S., \& Pentland, B. T. (2003). Reconceptualizing organizational routines as a source of flexibility and change. Administrative science quarterly, 48(1), 94-118.

Finkelstein, S., \& Hambrick, D. C. (1990). Top-management-team tenure and organizational outcomes: The moderating role of managerial discretion. Administrative science quarterly, 35(3), 484-503.

Fredrickson, J. W., \& Iaquinto, A. L. (1989). Inertia and creeping rationality in strategic decision processes. Academy of management journal, 32(3), 516-542.

Futrell, C. M., \& Parasuraman, A. (1984). The relationship of satisfaction and performance to salesforce turnover. Journal of Marketing, 48(4) , 33-40

García-Cabrera, A. M., \& García-Soto, M. G. (2012). Organizational commitment in MNC subsidiary top managers: antecedents and consequences. The International Journal of Human Resource Management, 23(15), 3151-3177.

Gertler, M., \& Wolfe, D. (Eds.). (2002). Innovation and social learning: institutional adaptation in an era of technological change. Springer.

Godkin, L. (2010). The zone of inertia: absorptive capacity and organizational change. The Learning Organization. 17(3), 196-207.

Gong, Y., Zhou, J., \& Chang, S. (2013). Core knowledge employee creativity and firm performance: The moderating role of riskiness orientation, firm size, and realized absorptive capacity. Personnel Psychology, 66(2), 443-482.

Grimes, R. (1994). The inertia gap: A threat to strategic planning?. Performance+ Instruction, 33(9), 19-21.

Gürbüz, S., \& Sahin, F. (2014). Sosyal bilimlerde arastırma yöntemleri. Seçkin Yayıncıllk, Ankara

Helfat, C. E. (Ed.). (2003). The SMS Blackwell handbook of organizational capabilities: Emergence, development, and change. Academy of Management 30(1), 1-11.

Hung, D. F. (2015). Sustained competitive advantage and organizational inertia: the cost perspective of knowledge management. Journal of the Knowledge economy, 6(4), 769-789.

Ingram, T. N., \& Lee, K. S. (1990). Sales force commitment and turnover. Industrial Marketing Management, 19(2), 149-154.

Kim, D., Wolf-Wendel, L., \& Twombly, S. B. (2013). The role of citizenship status in intent to leave for pre-tenure faculty. Journal of Diversity in Higher Education, 6(4), 245-260.

Kline, W., \& Wadhams, T. (2012). Overcoming competitive inertia: Board composition and strategic persistence. International Journal of Management \& Information Systems (IJMIS), 16(1), 111-124.

Koc, M., A. Aksoy, \& I. Ozturk. (2014). Entrepreneurial Behaviors: Are the People Restricted by Knowledge Inertia?. International Review of Management \& Marketing, 4 (1): 42-48.

KSO, (2020). Rakamlarla Konya [Online] https://www.kso.org.tr/sayfa/rakamlarla-konya-(Accessed:12 September 2019).

Kul, S. (2014). Uygun istatistiksel test seçim klavuzu. Plevra Bülteni, 8(2), 26-29.

Levene, H. (1960). Robust tests for equality of variances. In Ingram Olkin; Harold Hotelling; et al. (eds.). Contributions to Probability and Statistics: Essays in Honor of Harold Hotelling. Stanford University Press. pp. 278-292.

Liao, S. H., Fei, W. C., \& Liu, C. T. (2008). Relationships between knowledge inertia, organizational learning and organization innovation. Technovation, 28(4), 183-195.

Liao, S. H. (2003). Knowledge management technologies and applications-literature review from 1995 to 2002. Expert systems with applications, 25(2), 155-164. 


\section{S. Karayel 12/2 (2020) 1878-1894}

Liao, S. H. (2002). Problem solving and knowledge inertia. Expert systems with applications, 22(1), 21-31.

Matier, M. W. (1990). Retaining faculty: A tale of two campuses. Research in Higher Education, 31, 39-60.

Meyer, J.P., \& Allen, N.J. (1991). A three-component conceptualization of organizational commitment. Human Resource Management Review, 1(1), 61-89.

Mitchell, T. R., Holtom, B. C., Lee, T. W., Sablynski, C. J., \& Erez, M. (2001). Why people stay: Using job embeddedness to predict voluntary turnover. Academy of management journal, 44(6), 1102-1121.

Moraes Carvalho, D., Guarido Filho, E. ve de Almeida, V. E. (2018). Organizational performance and strategic inertia: The case of a Brazilian heavy construction company. REGE Revista de Gestão, 25(1). 25-46.

Nag, R., Corley, K. G., \& Gioia, D. A. (2007). The intersection of organizational identity, knowledge, and practice: Attempting strategic change via knowledge grafting. Academy of Management Journal, 50(4), 821-847.

O'Toole, P. (2010). How organizations remember: retaining knowledge through organizational action. (Vol. 2). Springer Science \& Business Media.

Pituch, K. A., \& Stevens, J. P. (2016). Applied multivariate statistics for the social sciences. NY: Routledge.

Rahman, H. \& Siswowiyanto, H. P. (2018). Knowledge Inertia in the Innovation of Coffee Production. The South East Asian Journal of Management, 12(2), 144-163.

Robertson, P. L., \& Langlois, R. N. (1994). Institutions, inertia and changing industrial leadership. Industrial and Corporate Change, 3(2), 359-378.

Rosin, H. M., \& Korabik, K. (1991). Workplace variables, affective responses, and intention to leave among women managers. Journal of Occupational Psychology, 64(4), 317-330.

Schwepker Jr, C. H. (2001). Ethical climate's relationship to job satisfaction, organizational commitment, and turnover intention in the salesforce. Journal of business research, 54(1), 39-52.

Shalikar, S., Lahoutpour, N., \& Rahman, A. B. A. (2011). The Study on the impact of knowledge inertia on organization. Australian Journal of Basic and Applied Sciences, 5(10), 1207-1213.

Sull, D. N., Tedlow, R. S. \& Rosenbloom, R. S. (1997). Managerial commitments and technological change in the US tire industry. Industrial and corporate change, 6(2), 461-500.

Tabachnick, B. G., Fidell, L. S., \& Ullman, J. B. (2007). Using multivariate statistics. (Vol. 5). Boston, MA: Pearson.

Thomke, S. \& Reinertsen, D. (1998). Agile product development: Managing development flexibility in uncertain environments. California management review, 41(1), 8-30.

Tripsas, M., \& Gavetti, G. (2000). Capabilities, cognition, and inertia: Evidence from digital imaging. Strategic management journal, 21(10-11), 1147-1161.

Tsai, S. B., Wu, W., Ma, S., Wu, C. H., \& Zhou, B. (2019). Benchmarking, knowledge inertia, and knowledge performance in different network structures. Enterprise Information Systems, 14(5), 1-20.

Turner, B. A., \& Chelladurai, P. (2005). Organizational and occupational commitment, intention to leave, and perceived performance of intercollegiate coaches. Journal of Sport Management, 19(2), 193-211.

Tushman, M. L. \& Anderson, P. (1986). Technological discontinuities and organizational environments. Administrative science quarterly, 31(3), 439-465.

Xie, X., Fang, L., Zeng, S., \& Huo, J. (2016). How does knowledge inertia affect firms product innovation? Journal of Business Research, 69(5), 1615-1620.

Wang, P. \& Yang, X. W. (2013). A review of knowledge inertia: How can we explain the hindrance on individual innovation. In International Academic Workshop on Social Science (IAW-SC-13). Atlantis Press 
Westphal, J.D. \& Frederickson, J.W. (2001). Who directs strategic change? Director experience, the selection of new CEOs and change in corporate strategy. Strategic Management Journal, 22(12), 1113-38.

$\mathrm{Wu}, \mathrm{W}$. W., \& Lee, Y. T. (2007). Selecting knowledge management strategies by using the analytic network process. Expert systems with Applications, 32(3), 841-847.

Zhou, K. Z., \& Li, C. B. (2012). How knowledge affects radical innovation: Knowledge base, market knowledge acquisition, and internal knowledge sharing. Strategic management journal, 33(9), 1090-1102. 